\title{
Sexual Violence against Women: Evaluating the Degree of Community Awareness
}

\author{
Authors \\ Dr Ajmari Sharmin ${ }^{1}$, Dr Tanusree Majumder², Dr Saima Akhtar Chowdhury ${ }^{3}$, \\ Dr Susmita Bhadra ${ }^{4}$, Dr Sumaia Subnum ${ }^{5}$, Dr Nilufar Yasmin ${ }^{6}$ \\ ${ }^{1,4}$ Department of Maternal and Child Health, NIPSOM, Dhaka, Bangladesh \\ ${ }^{2}$ MIS, DGHS, Mohakhali, Dhaka, Bangladesh \\ ${ }^{3}$ Department of Pathology, Faridpur Medical College Hospital, Bangladesh \\ ${ }^{5}$ SNMP Program, Save The Children, Bangladesh \\ ${ }^{6}$ DASCOH Foundation, Rajshahi, Bangladesh
}

\begin{abstract}
Violence against women (VAW) is a global phenomenon that exists beyond cultural, geographical, religious, social and economic context. In Bangladesh, sexual violence is an emblem of patriarchy in the guise of tradition and it has emphasized social, behavioural and structural misogyny that has been manifested day by day. It has become an important emerging issue which needs integrated community awareness and support to fight against it. This cross-sectional study aims at finding out the level of awareness regarding violence against women and was conducted among 191 community adult people aged 18 years old and above and those who satisfy the inclusion and exclusion criteria from 5th May, 2019 to 9th May, 2019 at the Dhamrai Upazilla in Dhaka district. With convenient sampling technique sample was selected and conducted face to face interview through semi structured questionnaire. In the study the majority of the respondent were female (5.8\%) and rest of them were male (48.2\%). We found that $39.8 \%$ people have poor knowledge about sexual violence where as $47.1 \%$ have average knowledge and $13.1 \%$ have good knowledge. Those who are economically solvent and service holder have better knowledge than others. A wide range of sociodemographic factors had a significant relationship with the knowledge of the respondents regarding sexual violence against women. As it happens in every community and affects people of all genders and ages; businesses, schools and community settings can create proactive policies to facilitate a safer environment.
\end{abstract}

Keywords: Sexual Violence, Community Awareness, Women.

\section{Introduction}

Violence against women is the violation of human rights. According to UN declaration on the Elimination of Violence against Women defines violence against women as:

Any act of gender based violence that results in physical, sexual or psychological harm or suffering to women including threats of such acts, coercion or arbitrary deprivation of liberty, whether occurring in public or in private life ${ }^{[1]}$. The root cause of violence against women is sexual inequality and it has such potentiality that woman from developed or under-developed society faces physical, sexual, psychological, economic violence in every stage of their lives ${ }^{[2]}$. It draws a line of demarcation among class and race, peace and conflicts. 
Sexual violence is the most heinous act against humanity. In past decades, a substantial proportion of sexual violence against women occurs within cohabiting, marital or other intimate relationships. But perpetrators of sexual violence are changing day by day. Now a woman, from her childhood to her elderly faces sexual violence from family members, neighbors, strangers, teachers, friends, colleagues, acquaintances. The effect of violence depend on the pattern, degree, period of violence even it might depend on the types of perpetrators; partner or non-partner ${ }^{[3]}$.

According to WHO globally, 35\% of women have experienced sexual intimate partner violence or nonpartner sexual violence. Almost one third (30\%) of all women who have been in a marital or other intimate relationship, have experienced sexual violence by their intimate partners. In some regions, $38 \%$ of all murders of women are committed by intimate partners. Worldwide, $7 \%$ women sexually assaulted by people other than partners. Sexual violence victims suffer from different health problems like unwanted pregnancy, unsafe abortion, low birth weight baby, HIV and other sexually transmitted diseases, stress, anxiety, depression ${ }^{[4]}$. Sexual violence victims face social challenges and obstacles. They are socially stigmatized and these social consequences become as extreme that their family feel shameful and dishonour to raise their voice against the crime. Sometimes, victims are blackmailed or forced to marry the perpetrator. They even become ostracized and this situation compels them to commit suicide [5].After marriage, being forced into sexual intercourse against her will is culturally acceptable in our society. So, a woman suffers lifelong sexual violence by her husband. Even women don't have the mentality that this harmful culture needs to be protested. So, constructive awareness needs to be built among us ${ }^{[6]}$. Child sexual abuse is most alarming. In major cases of violence, society attributes blame to the female victims. They are taunted for their infidelity, disobedience, failure as a wife, for their dressing sense or behavior, even when the victim is a child ${ }^{[7]}$.

\section{Materials and Methodology}

This Cross sectional study was conducted from 5th May, 2019 to 9th May, 2019 at the Dhamrai Upazilla in Dhaka district among 191 community adult people who were aged 18 years old and above and satisfied our inclusion and exclusion criteria.

A convenient sampling technique was used and data were collected through face to face interview using a semi-structured questionnaire consisting of three sections where section A contained the socio demographic data of the respondent's, section B comprises of questions eliciting information on the knowledge on sexual violence against women, section $\mathrm{C}$ comprises of question eliciting information on barrier and help seeking for the sexual violence.

The scores obtained from the instrument were subjected to simple descriptive statistics frequency, percentage and presented in tables.

\section{Results}

In this study we have 191 participants. Among them 92(48.2\%) were male and 99(52.8\%) were female. Mean age was $37.35( \pm 11.951)$ years. Out of 191 respondents $168(88 \%)$ were Muslim and 23(12\%) were Hindu. Mean duration of marriage was $18( \pm 10.438)$ years. Regarding marital status, $165(86.4 \%)$ were married, 21(11\%) were unmarried, $5(2.6 \%)$ were widowed. Among the 191 respondents $70(36.6 \%)$ participants have completed primary level of education, 55(28.8\%) have completed SSC, 24(12.6\%) have completed HSC, $21(11 \%)$ have completed graduation and $21(11 \%)$ are illiterate and below primary level of education. By income level, 81(42.4\%) women were housewife, $39(20.4 \%)$ are related business, $19(9.9 \%)$ are service-holder, 9(4.7\%) were students. Average monthly income of the respondents was BDT 21989 $( \pm 419) .111(58.1 \%)$ respondents were from nuclear family and $80(41.9 \%)$ were from combined family (Table 1).

According to the present study, most the respondents $(47.1 \%)$ have average knowledge regarding sexual violence, $39.8 \%$ have poor knowledge and $13.1 \%$ have good knowledge 


\section{JMSCR Vol||09||Issue |04||Page 08-13||April}

respectively (Figure 1). Among the respondents Housewife had $48.1 \%$, service holder had $68.4 \%$, and businessmen had $43.6 \%$ average level of knowledge, students $44.4 \%$ had good knowledge and others had $53.5 \%$ had poor knowledge on sexual violence (Table 2). Category of occupation of the respondents was found to be significantly associated with the knowledge of sexual violence $(\mathrm{p}=0.034)$. According to the present study among the respondents with family income (1000-10000) had $51.4 \%$ of average level of knowledge on sexual violence, family income (10001-20000) $46 \%$ had poor knowledge of sexual violence and family income (>20001) 49.3\% had average knowledge on sexual violence. Category of family income of the respondents was found to be significantly associated with the knowledge of sexual violence $(p=0.019)$.

\section{Level of Knowledge of All Sexual Violence}

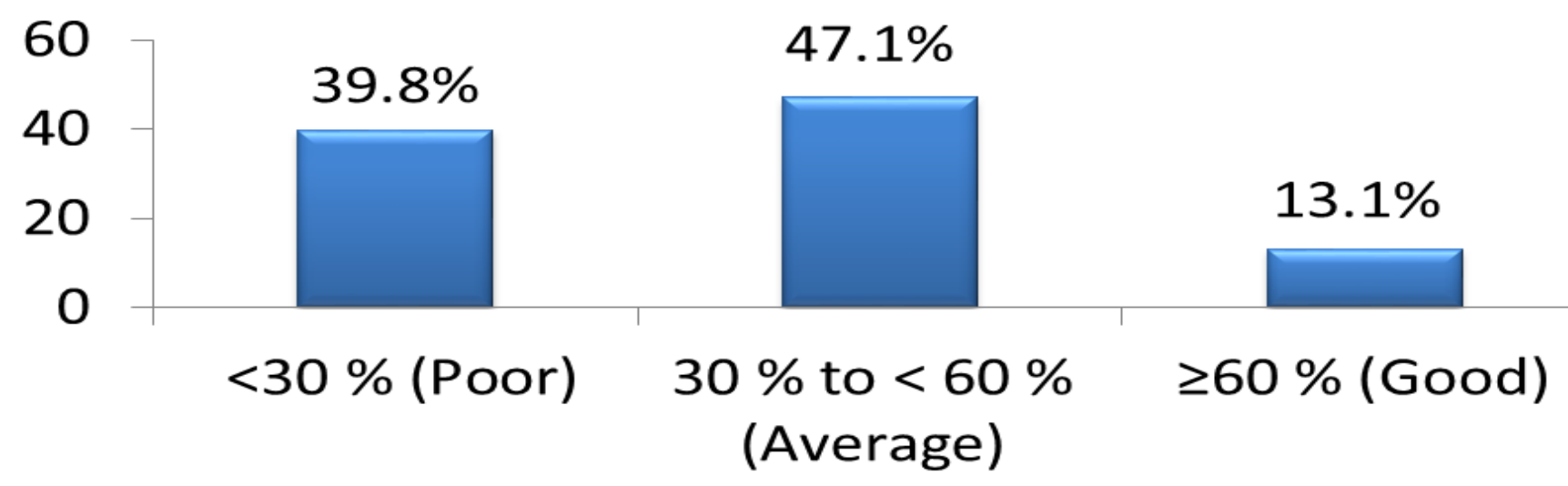

Figure 1: Level of knowledge regarding sexual violence among participants

Table 1: Socio-demographic characteristics of respondents

\begin{tabular}{|c|c|c|c|}
\hline Socio-demography & Category & $\mathbf{f}(\%)$ & Mean ( \pm SD) \\
\hline \multirow[t]{4}{*}{ Age } & $18-27$ years & $46(24.1 \%)$ & \\
\hline & $28-37$ years & $50(26.2 \%)$ & $37.35( \pm 11.951)$ \\
\hline & $38-47$ years & $56(29.3 \%)$ & \\
\hline & 48 years and above & $39(20.4 \%)$ & \\
\hline \multirow[t]{2}{*}{ Religion } & Islam & $168(88.0 \%)$ & \\
\hline & Hindu & $23(12.0 \%)$ & \\
\hline \multirow[t]{3}{*}{ Marital status } & Unmarried & $21(11 \%)$ & \\
\hline & Married & $165(86.4 \%)$ & \\
\hline & Widowed & $5(2.6 \%)$ & \\
\hline \multirow[t]{4}{*}{ Duration of marriage } & $1-12$ years & $56(29.3 \%)$ & \\
\hline & 13-24 years & $70(36.6 \%)$ & $18.41( \pm 10.438)$ \\
\hline & 25 years and above & $44(23.0 \%)$ & \\
\hline & Unmarried & $21(11 \%)$ & \\
\hline \multirow[t]{4}{*}{ Educational status } & Illiterate & $21(11 \%)$ & \\
\hline & Primary & $70(36.6 \%)$ & \\
\hline & SSC & $55(28.8 \%)$ & \\
\hline & Graduation and above & $21(11 \%)$ & \\
\hline \multirow[t]{5}{*}{ Occupational status } & Housewife & $81(42.4 \%)$ & \\
\hline & Services & $19(9.9 \%)$ & \\
\hline & Business & $39(20.4 \%)$ & \\
\hline & Student & $9(4.7 \%)$ & \\
\hline & Others & $43(22.5 \%)$ & \\
\hline \multirow[t]{3}{*}{ Monthly family income } & 1000 to $10000 \mathrm{BDT}$ & $37(19.4 \%)$ & \\
\hline & 10001 to $20000 \mathrm{BDT}$ & $87(45.5 \%)$ & 21989.53 \\
\hline & $20001 \mathrm{BDT}$ and above & $67(35.1 \%)$ & $( \pm 12391.419)$ \\
\hline \multirow[t]{2}{*}{ Family type } & Nuclear & $111(58.1 \%)$ & \\
\hline & Combined & $80(41.9 \%)$ & \\
\hline
\end{tabular}


Table 2: Association between occupational status and awareness regarding sexual violence among respondents

\begin{tabular}{|c|c|c|c|c|c|c|c|}
\hline \multirow[t]{2}{*}{ Distribution of all sexual violence scoring in category } & \multicolumn{5}{|c|}{$\begin{array}{l}\% \text { within distribution of the respondents according to } \\
\text { occupation category }\end{array}$} & \multirow[b]{2}{*}{ df } & \multirow[b]{2}{*}{ p value } \\
\hline & Housewife & Service & Business & Students & Others & & \\
\hline$<30 \%$ & $37 \%$ & $21.1 \%$ & $43.6 \%$ & $22.2 \%$ & $53.5 \%$ & & \\
\hline $30 \%$ to $60 \%$ & $48.1 \%$ & $68.4 \%$ & $43.6 \%$ & $33.3 \%$ & $41.9 \%$ & 8 & 0.034 \\
\hline$\geq 60 \%$ & $14.8 \%$ & $10.5 \%$ & $12.8 \%$ & $44.4 \%$ & $4.7 \%$ & & \\
\hline
\end{tabular}

\section{Discussions}

Victims of sexual violence faces multiple social and psychological challenges in Bangladesh. Rape and sexual violence are attacks on the body and dignity of a woman; such assaults have profound psychological, medical, economic, and social consequences for the rest of her life that plague survivors and their families.

The findings of the study shows, the level of community awareness regarding all four types of violence against women. The study also indicates a statistically significant relationship between a wide ranges of socio-demographic factors with the knowledge of the respondents regarding violence against women.

The main objective of this study was to find out level of community awareness regarding violence against women. In this study female (51.8\%) respondents were higher than the male $(48.2 \%)$ respondents. In the study majority $(29.3 \%)$ of the respondents were (38-47) years old. The mean age of the respondents was $37.35( \pm 11.47)$. The percentage of female were higher than the male. In this present study most of them were muslims (88\%)and this finding is consistent with previous study (Khatun S, 2013).In this study majority were married (86.4\%) with duration (13-24) years and mean years of married life $18.41(( \pm 10.43)$.This finding was not consistent with the previous study (Khatun S, 2013). In this study majority (36.6\%) of the respondents completed primary education. This finding was not consistent with the previous study (Haque S, 2007). In this study the majority of the respondent were housewife $(42.4 \%)$ followed by businessman (20.4\%) and other services. This finding is consistent with the previous study (Khatun S, 2013).In present study majority (45.5\%) of the respondents had family income between
(10000-20000) with the mean income 21989.53 $( \pm 12391.419)$. This finding is consistent with the previous study (Khatun S, 2013).

According to the present study Majority (13.1\%) of the respondents had good level of knowledge on sexual violence than the other violence. This finding is not consistent with the previous study (Haque $S$, 2007).

In our present study, among the respondents Housewife had $48.1 \%$, service holder had $68.4 \%$, Businessmen had $43.6 \%$, Students had $33.3 \%$ and others had $41.9 \%$ average level of knowledge on sexual violence. This study shows that, those who are in service category they have more average knowledge about sexual violence than the other 4 occupational category such as House wife, Businessmen, students \& others. The level of good knowledge about sexual violence present in the student category. Category of occupation of the respondent was found to be significantly associated with the knowledge of sexual violence $(\mathrm{p}=.034)$.

In our present study, among the respondents with family income (1000-10000) had 51.4\% of average level of knowledge on sexual violence. In case of respondents with family income (10000-20000) had $46.0 \%$ of poor level of knowledge on sexual violence. In case of respondents with family income ( $\geq 20000$ ) had $49.3 \%$ of average level of knowledge on sexual violence. This study shows that, good knowledge about sexual violence belongs to the income category group ( $\geq 20000$ ). Category of the family income of the respondent was found to be significantly associated with the knowledge of sexual violence $(\mathrm{p}=.019)$. Our study shows that occupations and economic status of family are the considerable predictor towards awareness about sexual violence. 


\section{Conclusions}

Sexual violence against women is relatively high in developing countries. The prevalence is increasing day by day with the increase of poverty, illiteracy, unemployment of both male and female. . In this backdrop of extreme insecurity that women face, it is difficult to envisage any real development in the country. If we are to realize our goal of greater participation of women in public spheres, women and children have to be safe in both public and private spaces. Interventions are needed to improve the educational status, economic status, women's autonomy. Society norms and practices regarding gender inequality need to be changed to allow a woman to enjoy her rights and to be free from all types of violence. This problem has a strong relationship with different socio-demographic factors of the people of the community as both the victims and the perpetrators belong to the community. If we don't raise our voice against all these abuse, mishaps, it will flare up the situation. Building sexual equality and empowering women is the important development goal for governments across the world to reduce sexual violence against women. Different laws and legislations are already enacting to serve the purpose. Sex education, sexual and reproductive health information, community awareness and response against violence is more important for our own safety and security. The government should ensure that this woman, and all sexual assault survivors, are treated with dignity and have access to psychosocial services, and that their right to a fair, timely, independent investigation and adequate legal remedy is respected. By serving all these, we will be able to make a world safer, healthier and better place to live for women.

\section{Acknowledgement}

We are precisely indebted and uttering a heartfelt gratitude to the respondents of Dhamrai Upazila, Dhaka. Without their co-operation and sincerity the study would not be possible and see the light of completion.

\section{Declarations}

Funding: This research protocol was self-funded.

Conflict of Interest: No competing interests relevant to this study to disclose for all authors. Full forms submitted and on file for all authors.

Ethical Approval: The objectives and importance of the research were explained to all participants prior to recruitment. Participation in the study was voluntary. The confidentiality of the participants was maintained, and written informed consent as well as ascent was obtained from all participants. The study was approved by the Institutional Review Board (IRB) of the National Institute of Preventive and Social Medicine (NIPSOM) and obtained an ethical clearance waiver from same source.

\section{References}

1. Declaration on the Elimination of Violence against Women, Proclaimed by General Assembly resolution 48/104 of 20 December 1993. Available at:

https://www.un.org/en/genocideprevention/doc uments/atrocity-

crimes/Doc.21_declaration\%20elimination\%20 vaw.pdf

2. Culbertson, K. A. and Dehle, C. (2001) 'Impact of Sexual Assault as a Function of Perpetrator Type', Journal of Interpersonal Violence, 16(10), pp. 992-1007.

doi: 10.1177/088626001016010002

3. Watts, Charlotte et al., Violence against women: global scope and magnitude, The Lancet, Volume 359, Issue 9313, 1232 - 1237

4. The World Health Organization (WHO), Global and regional estimates of violence against women (2013). Available at: https://www.who.int/publications/i/item/97892 41564625

5. Garcia-Moreno C, Watts C. Violence against women: its importance for HIV/AIDS prevention. AIDS. 2000; 14(Suppl3):253-265.

6. Puri M, Frost M, Tamang J, Lamichhane P, Shah I. The prevalence and determinants of sexual violence against young married women by husbands in rural Nepal. BMC Res Notes. 
2012; 5:291. Published 2012 Jun 13. doi:10.1186/1756-0500-5-291

7. Watts C, Zimmerman C. Violence against women: global scope and magnitude. Lancet. 2002 Apr 6; 359(9313):1232-7. doi: 10.1016/S0140-6736(02)08221-1. PMID: 11955557.

8. Khatun S, M.T \& Rahman, K.F. (2013). Domestic Violence against Women in Bangladesh: Analysis from a Socio-legal Perspective. Bangladesh e-Journal of Sociology, 9(2), 19-30.

9. Haque S \& Subia Dolores Big Foot (2007) Violence and the Effects of Trauma on American Indian and Alaska Native Populations, Journal of Emotional Abuse, 8:1-2, 51-66, DOI: 10.1080/10926790801982410. 